\title{
A VIDA DO CRIATIVO DE NOVO HAMBURGO/RS: \\ Um Estudo Baseado em Talento, Tolerância e Tecnologia ${ }^{1}$
}

Mauricio BARTH ${ }^{2}$

Cristiano Max Pereira PINHEIRO ${ }^{3}$

\begin{abstract}
${ }^{1}$ Estudo vinculado aos Grupos de Pesquisa "O processo de consolidação da Indústria Criativa no Rio Grande do Sul" (Universidade Feevale) e "Universidade Criativa: o papel das IES como território de desenvolvimento da Indústria Criativa no Rio Grande do Sul" (CNPq).

${ }^{2}$ Mestre em Indústria Criativa (Universidade Feevale); e-mail: mauricio@feevale.br.

${ }^{3}$ Doutor em Comunicação Social (PUCRS); coordenador dos Cursos de Jornalismo, Relações Públicas e Publicidade e Propaganda e professor do Mestrado em Indústria Criativa (Universidade Feevale); e-mail: maxrs@ feevale.br.
\end{abstract}

Recebido em: 02/11/2015 - Aprovado em: 15/07/2016 - Disponibilizado em: 18/12/2016

\begin{abstract}
RESUMO
O presente trabalho objetiva dar continuidade a um diagnóstico iniciado em maio de 2014 que, em um primeiro momento, contemplou dados demográficos e ambientais dos trabalhadores da área criativa de Novo Hamburgo/RS, demonstrando, entre outros pontos, que grande parte da mão-de-obra inventiva da cidade é oriunda das Instituições de Ensino Superior da região. Dando sequência à pesquisa, o atual estudo visa demonstrar o perfil do profissional hamburguense enquanto criativo, abordando aspectos referentes aos 3Ts descritos por Florida (2014): Talento, Tolerância e Tecnologia. Para fins metodológicos, mapeou-se o número total de criativos na cidade (2011) e, através de um cálculo amostral, estabeleceu-se a quantidade final de entrevistados (323). Ao fim da pesquisa, que contou com 339 respondentes, constata-se que os trabalhadores da Indústria Criativa de Novo Hamburgo afirmam, em sua maioria, que trocar experiências com profissionais do ramo é a maior forma de desenvolver talentos criativos. Além disso, os mesmos externam-se tolerantes, ouvindo opiniões de funcionários de outras áreas, ao mesmo tempo em que se mostram abertos ao convívio profissional e pessoal com pessoas de credos, raças, orientações sexuais e regiões diferentes. Ainda, ratificam que os atuais aparatos tecnológicos existentes contribuem para seu desenvolvimento criativo; por outro lado, atestam que Novo Hamburgo possui uma boa estrutura tecnológica, contudo, a cidade precisa, ainda, melhorar bastante. Palavras-chave: Indústria Criativa. Trabalhadores Criativos. Novo Hamburgo/RS.
\end{abstract}

\section{CREATIVE'S LIFE OF NOVO HAMBURGO/RS:}

\section{A Study Based on Talent, Tolerance and Technology}

\begin{abstract}
This work aims to continue a diagnosis started in may 2014 that, at first, included demographic and environmental data of workers from the creative area of Novo Hamburgo/RS, demonstrating, among other points, that much of the work inventive city comes from the Higher Education Institutions in the region. Continuing research, the current study aims to demonstrate the profile hamburguense while creative professional, covering aspects related to 3Ts described by Florida (2014): Talent, Technology and Tolerance. For methodological purposes, mapped the total number of creatives in the city (2011) and, through a sample calculation, settled the final number of respondents (323). At the end of the survey, which included 339 respondents, it appears that employees of Creative Industry Novo Hamburgo say, mostly to exchange experiences with industry professionals is the greatest way to develop creative talents. In addition, they externalize were tolerant hearing opinions of officials from other areas, while that show open to professional and personal interaction with people of creeds, races, sexual orientations and different regions. Also confirm that the current existing technological devices contribute to his creative development; on the other hand, show that Novo Hamburgo has a good technological infrastructure, however, the city still needs to improve a lot.
\end{abstract}

Keywords: Creative Industry. Creative workers. Novo Hamburgo/RS. 


\section{INTRODUÇÃO}

Embora sua prática seja antiga, foi na década de 1990 que seu conceito ganhou força. Surgida na Austrália, mas propagada pelo Reino Unido, a Indústria Criativa destaca-se por possuir no capital intelectual sua matériaprima; é a arte das boas ideias, do novo, do pensar diferente. Sendo assim, este artigo propõe uma análise acerca desta nova - porém, já consolidada - forma de mensurar um dos maiores bens intangíveis que a sociedade contemporânea possui: a criatividade.

Sob um prisma brasileiro, Reis (2012) disserta que, em cada localidade do País, o conceito ganha força e surgem novas demonstrações do potencial econômico que a Indústria Criativa pode prover. Dessa forma, o presente trabalho objetiva dar continuidade a um estudo iniciado em maio de 2014 que, em um primeiro momento, contemplou dados demográficos e ambientais dos trabalhadores da área criativa de Novo Hamburgo/RS. A sequência deste estudo, apresentada a seguir, visa demonstrar o perfil do profissional hamburguense enquanto criativo, abordando aspectos referentes aos 3Ts descritos por Florida (2014): Talento, Tolerância e Tecnologia. Além do referido autor, são utilizados, ainda, conceitos de Howkins (2002), Bendassolliet al. (2009), Deheinzelin (2011), Reis (2012), entre outros.

O estudo está estruturado da seguinte forma: a próxima seção traz à tona as questões relativas à Indústria Criativa e aos 3Ts propostos por Florida (2014), buscando construir uma base sólida para as discussões que serão propostas na análise. A metodologia empregada é destacada na seção seguinte, demonstrando os critérios utilizados pelos pesquisadores para a construção deste trabalho. $\mathrm{Na}$ sequência, a próxima seção destaca a análise deste estudo, com elementos referentes à coleta dos dados e, posteriormente, um aprofundamento analítico buscando, sobretudo, compreender o atual cenário criativo na cidade de Novo Hamburgo/RS. Por fim, destacam-se as considerações finais e as referências utilizadas nesta investigação.

\section{A INDÚSTRIA CRIATIVA E OS 3TS - TALENTO, TOLERÂNCIA E TECNOLOGIA}

No final dos anos 1990, o Departamento de Cultura, Mídia e Esportes (DCMS) do Reino Unido lançou um mapeamento da Indústria Criativa, cunhando, assim, um novo conceito, demonstrando que determinadas empresas podem ir além de seu papel cultural e podem, de maneiras mercadológicas, gerar valores consideráveis (HOWKINS, 2002).

O termo, de forma sucinta, refere-se a uma indústria onde o trabalho criativo é preponderante e onde o resultado alcançado é a propriedade intelectual (BENDASSOLLI et al., 2009). Deheinzelin (2011) define a Indústria Criativa como uma economia baseada em recursos intangíveis, já que sua principal matéria-prima é a ideia. Para a autora, nunca 
chegaremos, inclusive, a uma real definição da área e estaremos, sempre, em uma "versão Beta". Contudo, não possuir um conceito definitivo e absoluto pode, de alguma forma, ser benéfico pois, neste caso, cada local adequa-se à significação que mais lhe convém (REIS, 2012).

Embora os conceitos tenham inúmeras redações, há um elemento central em destaque: a criatividade; é através dela que, conforme Simonton (2000), novos negócios surgem e a economia pode avançar em sentidos exponenciais. Para Nicolaci-da-Costa (2011), a criatividade é o componente-chave para a difusão dos negócios do futuro, atraindo olhares dos mais diversos campos.

Alicerçando-se na compreensão de localidades que fomentem a criatividade, Florida (2014) argumenta que um território que busca desenvolver-se de maneira exponencialmente criativa deve, necessariamente, possuir 3Ts: Talento, Tolerância e Tecnologia. Para o autor, este é o local onde os criativos querem viver: um espaço repleto de boas oportunidades, qualidade de vida e desenvolvimento econômico.

Na dimensão do Talento, o autor destaca questões como estrutura disponível para que os criativos possam desenvolver-se através de cursos de extensão, graduação e pós-graduação. Ainda, é importante que a cidade ofereça opções de lazer, que, conforme Reis (2012), são fundamentais para o avanço de um perfil criativo. Cinema, teatro e shows musicais contribuem para a formação de uma base criativa, fornecendo elementos referenciais no aprimoramento dos profissionais (DEHEINZELIN, 2011).

Outra questão fundamental, segundo Florida (2014), é o aspecto relacionado à Tolerância, a qual, refere o autor, trata-se de demonstrações complacentes a discussões de credo, cor, orientação sexual e/ou discriminações das mais diversas. Uma cidade que busca seu desenvolvimento criativo deve, a partir de demonstrações evidentes de indulgência, mostrar-se receptiva às mais díspares manifestações humanísticas (ASHEIM;HANSEN, 2009).

Quanto à Tecnologia, as cidades devem possuir elementos que possibilitem a expansão da ciência, desde polos tecnológicos até internet banda larga de boa qualidade a usuários domésticos. Somente munidos de aparatos tecnológicos oportunos, os criativos podem agregar valor a sua formação, contribuindo, dessa forma, para transformar a cidade em que vivem em um grande território de criatividade (NICOLACI-DA-COSTA, 2011).

A seção seguinte objetiva demonstrar os métodos utilizados neste trabalho.

\section{PROCEDIMENTOS METODOLÓGICOS}

A presente seção tem por objetivo apresentar o percurso metodológico a ser trilhado para a realização desta pesquisa. 
Inicialmente, o estudo buscou levantar informações referentes à quantidade de criativos presentes em cada um dos segmentos que compõem a Indústria Criativa em Novo Hamburgo/RS. Para isso, utilizou-se, como base, um estudo realizado pela FIRJAN Federação das Indústrias do Rio de Janeiro, o qual mapeou diversas cidades do País, buscando definir o cenário criativo das mesmas. Ao acessar o site disponibilizado pela Instituição, é possível filtrar a busca selecionando itens como ano ${ }^{1}$, estado, município e segmento. A seguir, demonstramse os resultados da busca realizada.

Tabela 1 - Segmentos e o número de criativos em Novo Hamburgo/RS

\begin{tabular}{lc}
\hline Segmentos & Números \\
\hline Arquitetura \& Engenharia & 142 \\
Artes & 58 \\
Artes Cênicas & 11 \\
Biotecnologia & 22 \\
Design & 454 \\
Expressões Culturais & 52 \\
Filme \& Vídeo & 45 \\
Mercado Editorial & 220 \\
Moda & 360 \\
Música & 13 \\
Pesquisa \& & \\
Desenvolvimento & 49 \\
Publicidade & 170 \\
Software, Computação \& & \\
Telecom & 369 \\
Televisão \& Rádio & 46 \\
\hline Total & $\mathbf{2 0 1 1}$ \\
\hline
\end{tabular}

Fonte: Elaborado pelos autores, com base em FIRJAN (2011)

${ }^{1}$ Os anos disponibilizados para consulta no site da FIRJAN são 2010 e 2011. Optou-se, nesta pesquisa, pelo ano de 2011.
Após estabelecer o valor total (2011 criativos), realizou-se um cálculo amostral para saber quantos trabalhadores da Indústria Criativa de Novo Hamburgo deveriam participar da pesquisa. Com uma margem de $5 \%$ de erro, o valor demonstrado pelo cálculo foi de 323 criativos a serem questionados. Concomitantemente a este processo, elaborouse um questionário, o qual contemplava questões que serão discutidas posteriormente na análise. Contudo, antes da aplicação efetiva, realizou-se um pré-teste ${ }^{2}$ com 5 criativos selecionados pelos pesquisadores. Os mesmos foram convidados a responder a pesquisa, que foi enviada via e-mail e, após, em horário e local previamente combinados, apontaram sugestões aos pesquisadores, visando o aprimoramento do estudo.

Quadro 1 - Criativos e seus segmentos dentro da Indústria Criativa

\begin{tabular}{|c|c|c|}
\hline Criativos & $\begin{array}{c}\text { Segmento } \\
\text { dentro da } \\
\text { Indústria } \\
\text { Criativa }\end{array}$ & Profissão \\
\hline 1 & $\begin{array}{c}\text { Mercado } \\
\text { Editorial }\end{array}$ & Jornalista \\
\hline 2 & Moda & PersonalStylist \\
\hline 3 & Artes & Artista Plástica \\
\hline 4 & Publicidade & Diretor de Arte \\
\hline 5 & Design & Webdesigner \\
\hline
\end{tabular}

Nota: optou-se por manter os nomes dos criativos que contribuíram com o pré-teste em sigilo

Fonte: Elaborado pelos autores

Posteriormente, o questionário foi, de maneira oficial, postado no perfil dos

\footnotetext{
${ }^{2} \mathrm{O}$ pré-teste refere-se ao teste do questionário em uma pequena amostra de entrevistados, com o objetivo de identificar e eliminar problemas potenciais (PRODANOV; FREITAS, 2013).
} 
pesquisadores na rede social Facebook ${ }^{3}$, buscando coletar a amostra desejada (323 criativos). Após o post inicial, que foi realizado no dia 15 de maio de 2014, estabeleceu-se que a pesquisa estaria disponível online durante 30 dias. Ao fim do período, os números demonstravam que 339 pessoas haviam respondido. Em seguida, iniciou-se a tabulação dos dados, as quais geraram os resultados que serão discutidos na seção adiante.

\section{RESULTADOS E ANÁLISE}

\subsection{OBJETO DO ESTUDO DE CASO: NOVO} HAMBURGO/RS

O município de Novo Hamburgo, fundado em 5 de abril de 1927, localiza-se a $47 \mathrm{~km}$ de Porto Alegre/RS. Possui, atualmente, 239.051 habitantes, com um PIB geral de R\$ 4.499.416 e um PIB per capita de R\$ 17.456,78. O cenário econômico do município divide-se entre indústrias, comércio e prestação de serviços, com, no momento, 3.029 indústrias, 8.897 comércios e 13.945 serviços ${ }^{4}$.

\footnotetext{
${ }^{3}$ Justifica-se a escolha do Facebook por ser considerada, hoje, a mais representativa rede social do mundo (RYAN; XENOS, 2011; Junco, 2013).

${ }^{4}$ Disponível em:

<http://www.ibge.gov.br/home/default.php>. Acesso em: 01 mar. 2014
}

Figura 1 - Localização de Novo Hamburgo no Rio Grande do Sul

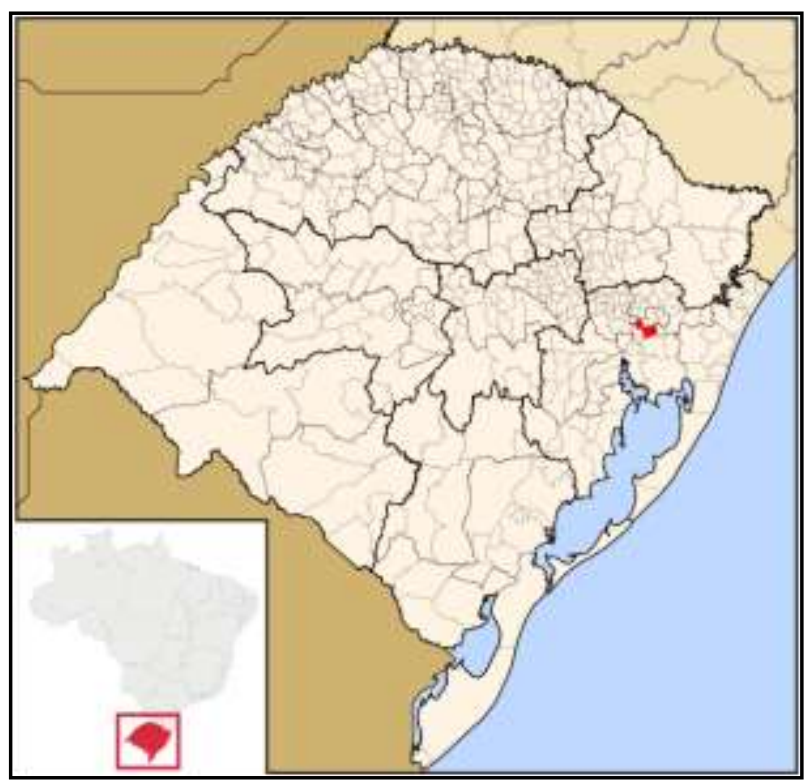

Fonte: Novo Hamburgo $(2014, \text { online })^{5}$

A cidade é conhecida como "A capital nacional do calçado", pois, devido à significativa produção de sapatos, tornou-se referência neste segmento (SCHEMES et al., 2005). Destaca-se, também, por possuir um clube de futebol - o Esporte Clube Novo Hamburgo - disputando a Série A do Campeonato Gaúcho. Inclusive, no ano de 2014, o clube cedeu seu estádio ao Sport Club Internacional para que o mesmo disputasse suas partidas, enquanto sua arena estava em reformas para a Copa do Mundo do Brasil. Esse fato movimentou o cenário esportivo da região onde a cidade está inserida. $\mathrm{O}$ município conta, também, com Instituições de Ensino Superior, destacando-se a Universidade Feevale, que oferece inúmeras opções de cursos em todos os níveis de ensino (inclusive, com variados

\footnotetext{
${ }^{5}$ Disponível em:

<http://www.novohamburgo.rs.gov.br/>. Acesso em: 01 mar. 2014.
} 
cursos oriundos da Indústria Criativa) ${ }^{6}$. Potts e Cunningham (2010) defendem que as Universidades são polos fundamentais de disseminação da identidade criativa, proporcionando, à região, inúmeros benefícios provenientes de uma cultura que visa promover novos negócios e empreendimentos baseados nas ideias e na inventividade.

\section{RESULTADOS E ANÁLISE}

\subsection{Dimensão 1: Talento}

Inicialmente, questionou-se os entrevistados sobre os itens que consideravam úteis para o desenvolvimento de seus talentos criativos, solicitando que os mesmos demonstrassem seu grau de satisfação com as opções oferecidas em Novo Hamburgo. Quando perguntados sobre "Cursos superiores", a maior parte atribuiu o grau 4 (32\%), sendo o grau 1 estabelecido como "pouco satisfeito" e o grau 5 como "muito satisfeito". Quanto aos "Cursos livres", a resposta mais assinalada foi o grau 3, totalizando 36\%. Sobre "Eventos", incluindo congressos, seminários, workshops, entre outros, o grau 2 teve o maior número das respostas, com 37\%. O mesmo grau foi atribuído ao item "Cinema", que apresentou $34 \%$, assim como "Teatro", que apresentou $30 \%$ dos entrevistados. No que diz respeito aos shows musicais, os graus 1, 2 e 3

\footnotetext{
${ }^{6}$ Disponível em: <http://www.feevale.br/ensino〉. Acesso em: 01 mar. 2014.
}

demonstraram equilíbrio, com 26\%, $26 \%$ e $27 \%$, respectivamente. Já a "Internet banda larga" teve no item 3 o seu maior número de respondentes, com $31 \%$.

Tabela 2 - Pergunta: Considerando os itens abaixo úteis para o desenvolvimento de talentos criativos, demonstre seu grau de satisfação com as opções oferecidas em Novo Hamburgo (em \%)

\begin{tabular}{|c|c|c|c|c|c|c|}
\hline & 1 & 2 & 3 & 4 & 5 & $\begin{array}{c}\text { Não } \\
\text { sei/Não } \\
\text { se } \\
\text { aplica }\end{array}$ \\
\hline $\begin{array}{l}\text { Cursos } \\
\text { superiores }\end{array}$ & 7 & 16 & 27 & 32 & 18 & 0 \\
\hline Cursos livres & 17 & 25 & 36 & 14 & 6 & 2 \\
\hline $\begin{array}{l}\text { Eventos } \\
\text { (congressos, } \\
\text { seminários, } \\
\text { workshops } \\
\text { etc) }\end{array}$ & 20 & 37 & 26 & 9 & 7 & 1 \\
\hline Cinema & 17 & 34 & 27 & 15 & 5 & 2 \\
\hline Teatro & 20 & 30 & 24 & 19 & 4 & 3 \\
\hline $\begin{array}{l}\text { Shows } \\
\text { musicais }\end{array}$ & 26 & 26 & 27 & 16 & 4 & 1 \\
\hline $\begin{array}{l}\text { Internet banda } \\
\text { larga }\end{array}$ & 14 & 19 & 31 & 22 & 12 & 2 \\
\hline
\end{tabular}

Nota inserida na questão: (entende-se 1 como "pouco satisfeito" e 5 como "muito satisfeito")

Fonte: Elaborado pelos autores

Dando continuidade, questionou-se o público respondente da pesquisa sobre qual elemento era considerado essencial para o desenvolvimento de um diferencial criativo. Os entrevistados responderam, em sua maioria, que "trocar experiências com profissionais do ramo" é algo fundamental nos segmentos profissionais que envolvem a criatividade (55\%). As respostas "Estagiar na área", "Fazer cursos de aprimoramento" e "Realizar intercâmbio para outros países/regiões" 
demonstraram equilíbrio, apresentando 15\%, $16 \%$ e $14 \%$, respectivamente.

Gráfico 1 - Qual elemento você considera essencial para o desenvolvimento de um diferencial criativo? (em \%)

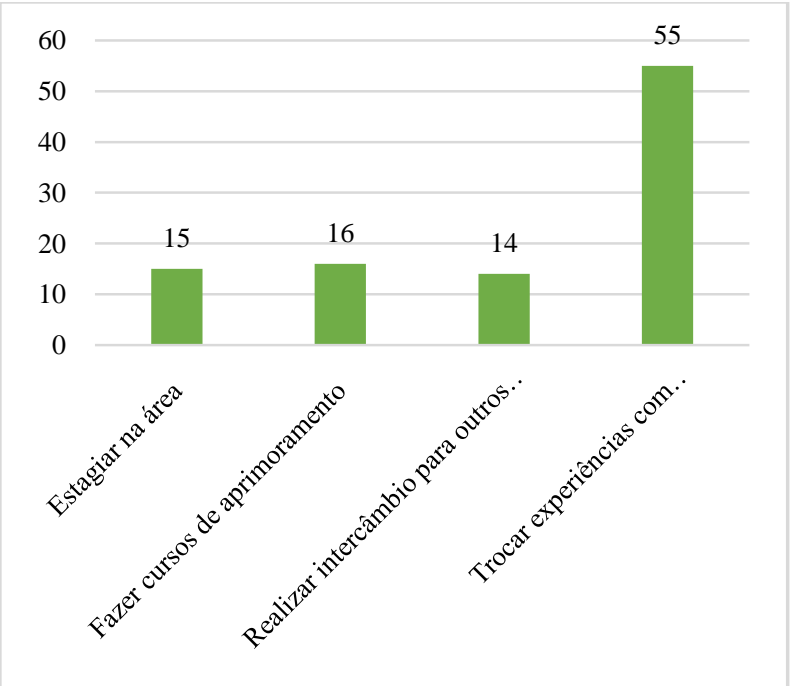

Fonte: Elaborado pelos autores

\subsection{Dimensão 2: Tolerância}

Quando perguntados se, diante de situações que envolvam soluções criativas, os entrevistados ouvem opiniões de pessoas desvinculadas à área da criatividade, os mesmos responderam, em maioria imensa, que "Sim! Qualquer contribuição, independente da área, é sempre bem-vinda", com 93\% das respostas. A afirmativa "Não! Pessoas de áreas que não estimulem a criatividade podem atrasar e atrapalhar o processo" teve apenas 7\%.
Gráfico 2 - Perante um problema que envolva uma solução criativa, você ouve opiniões de pessoas desvinculadas à área da criatividade? (em \%)

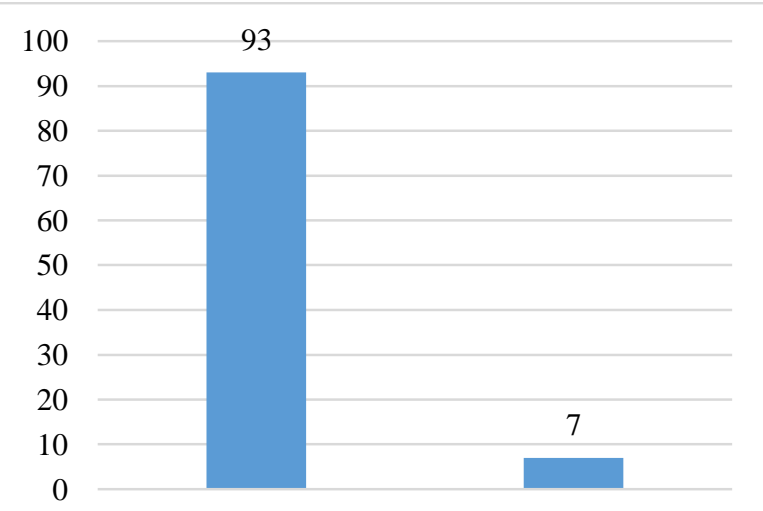

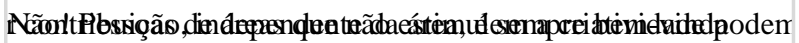

Fonte: Elaborado pelos autores

$\mathrm{Na}$ sequência, a pesquisa perguntou sobre ser tolerante em relação às diversidades culturais no convívio profissional e pessoal dos criativos. Uma parte significativa (80\%) respondeu "Sim! Sou bem aberto às diversidades culturais”. A opção "Em parte! Às vezes sou um pouco reticente ao assunto" teve $19 \%$, enquanto "Não! Costumo ser intolerante a questões deste tipo" obteve apenas $1 \%$ das respostas. 
Gráfico 3 - Você se considera tolerante às diversidades culturais em seu convívio profissional e pessoal? ${ }^{7}(\mathrm{em} \%)$

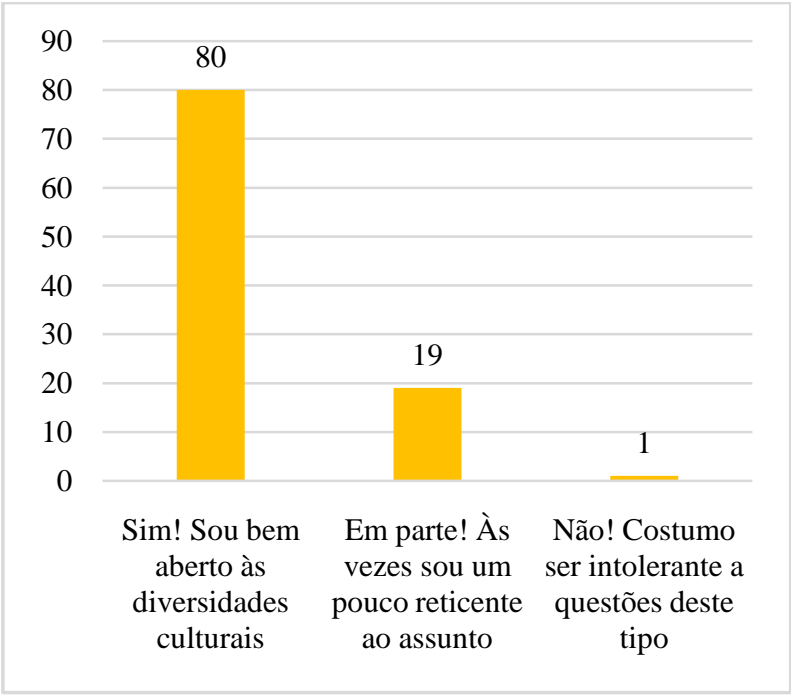

Fonte: Elaborado pelos autores

\subsection{Dimensão 3: Tecnologia}

Buscou-se, através das perguntas seguintes, adquirir dados referentes à tecnologia na cidade Novo Hamburgo. Sendo assim, interrogou-se os entrevistados sobre os aparatos tecnológicos existentes e sua contribuição para o desenvolvimento criativo. A maioria significativa apontou que "Sim! A tecnologia me ajuda a pensar 'fora da caixa"', demonstrando que $92 \%$ dos interrogados está inserida na tecnologia atual, o que, conforme cita Florida (2014), é algo essencial para o desenvolvimento dos potenciais criativos dos trabalhadores da área.
Gráfico 4 - Os aparatos tecnológicos existentes contribuem para seu desenvolvimento criativo? (em \%)

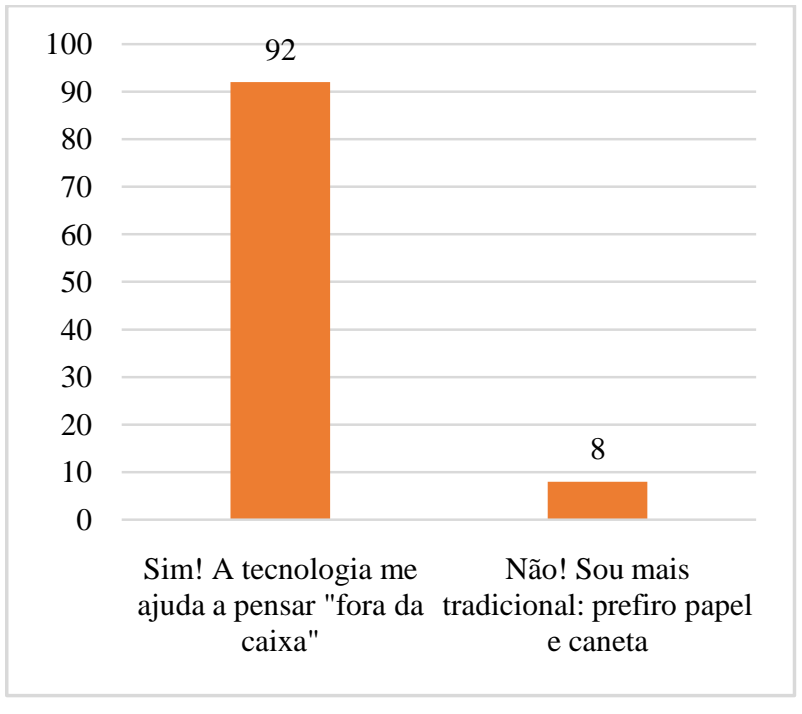

Fonte: Elaborado pelos autores

Questionando-os, ainda, sobre a tecnologia na cidade, os respondentes assinalaram que Novo Hamburgo tem "uma boa estrutura tecnológica, contudo, é preciso melhorar bastante" (59\%). Destaca-se, ainda, a opção "Não! Novo Hamburgo é uma cidade defasada em termos de tecnologia", que recebeu $40 \%$ das respostas, demonstrando certa insatisfação do público entrevistado, já que, inclusive, apenas $1 \%$ respondeu que "Sim! Temos uma tecnologia de ponta na cidade".

\footnotetext{
${ }^{7}$ Nota inserida na pergunta: A questão refere-se à convivência com pessoas de credos, raças, orientações sexuais e regiões diferentes.
} 


\section{Gráfico 5 - Você considera Novo Hamburgo uma} cidade tecnológica? (em \%)

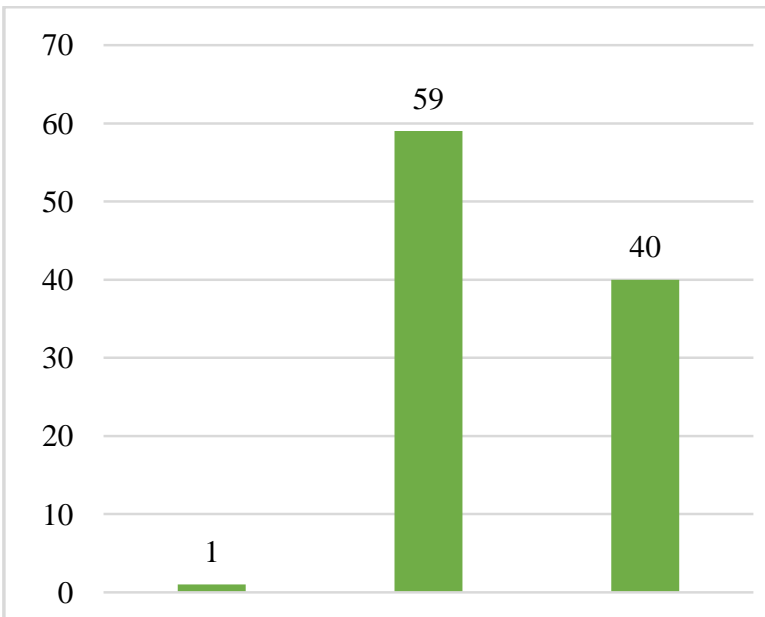

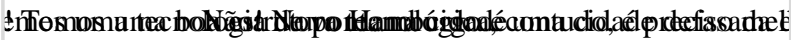

Fonte: Elaborado pelos autores

\subsection{Empregabilidade e empreendedorismo}

Encaminhando-se para o final da pesquisa, buscando complementar a mesma, interrogouse os entrevistados sobre questões relativas ao perfil empreendedor dos mesmos, assim como a empregabilidade na cidade. Ao serem perguntados se trocariam de emprego, ganhando menos como funcionário em uma startup, apenas pela oportunidade de exercitar os seus talentos, os respondentes, em sua maioria, apontaram que "Sim! O que vale é a realização pessoal!”, com 49\%. Já para 31\%, a resposta assinalada diz que "Não! Sem dinheiro, sem chance!”. Nessa questão permitiu-se a assinalação da opção "Outros", a qual teve $20 \%$ das respostas sendo que algumas delas ilustram o Quadro 2.
Gráfico 6 - Você trocaria de emprego, ganhando menos como funcionário em uma startup, apenas pela oportunidade de exercitar os seus talentos? (em \%)

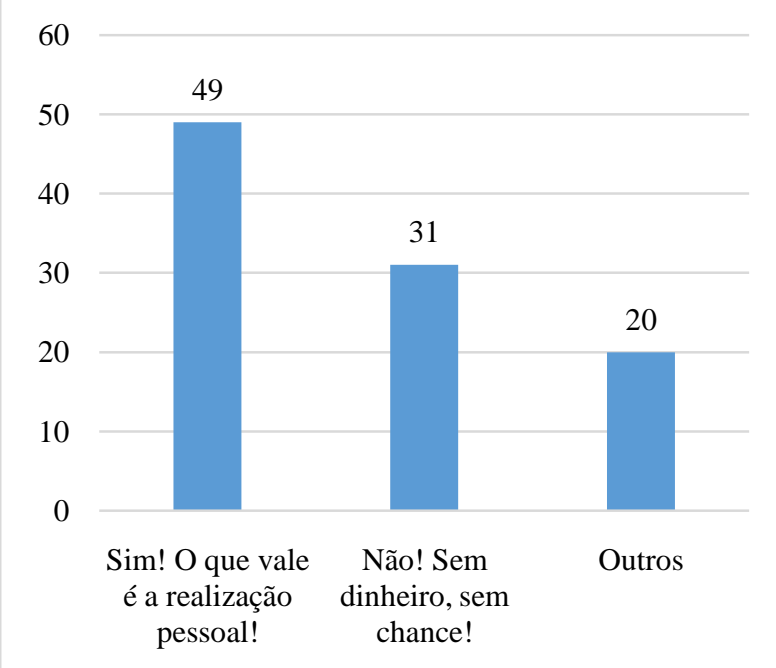

Fonte: Elaborado pelos autores

Quadro 2 - Quadro-síntese das respostas dos entrevistados que assinalaram a opção "Outro" "Depende muito. Eu me apaixonei e abracei a causa." “Dependeria da temática da startup ser sedutora."

"Dependendo da proposta da startup e do planejamento de ganhos a médio prazo."

"Dependeria do momento de vida e de outras ofertas apresentadas."

"No momento não, pois tenho que sustentar minha família, mas se não fosse este o problema eu trocaria sim."

"Em parte, só se a oportunidade realmente valer a pena, se meu trabalho será visto por um público grande, chegue à mais lugares, seria uma boa troca."

"Nesse momento não, pois preciso de dinheiro no curto prazo para aperfeiçoamento profissional."

"Depende. Hoje o dinheiro pesaria, mas abriria mão de parte dele se vislumbrasse um futuro próspero."

"Talvez, qualidade de vida é algo que estou considerando."

"Sim. Todo risco calculado é bem-vindo, afinal, estamos falando de uma startup que pode vir a ter sucesso financeiro."

"Já troquei colocações estáveis por projetos desafiadores, mas sempre projetos próprios ou coempreendimentos com parceiros. Hoje em dia, o fator financeiro pesa muito mais."

Fonte: Elaborado pelos autores

Quando questionados se deixariam um emprego estável e com bom salário para abrir 
uma empresa própria, onde pudesse colocar em prática as suas ideias criativas, os respondentes assinalaram, em sua maioria, que "Sim! Tenho ‘peito' para isso!”, com 63\%. Já a opção “Não! É algo muito arriscado nos dias de hoje!"obteve $22 \%$ das respostas, valor próximo a opção "Outro", que contou com 15\% e tem alguns de seus comentários destacados no Quadro 3.

Gráfico 7 - Você deixaria um emprego estável e com bom salário para abrir uma empresa própria, onde pudesse colocar em prática as suas ideias criativas? (em \%)

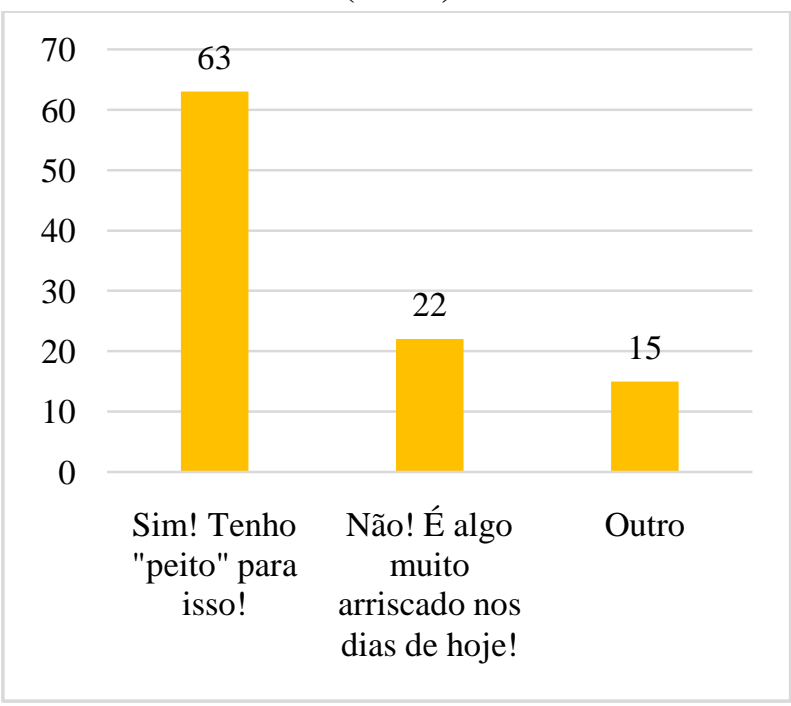

Fonte: Elaborado pelos autores

Quadro 3 - Quadro-síntese das respostas dos entrevistados que assinalaram a opção "Outro"

"Sim, como trabalho e fonte de remuneração secundária."

"Com uma ideia bastante estruturada, sim."

"Não, mas não por achar arriscado e sim por não ter competência para ser chefe."

"Não, porque não tenho este interesse neste momento."

"Talvez, se estivesse estabilizada financeiramente para isso."

"Já fiz isso mas infelizmente não deu certo. Preciso recuperar o prejuízo antes de retornar."

"Depende da perspectiva de cada negócio."
"Depende! Não adianta abrir uma empresa sabendo o resultado que se quer sem saber como atingi-lo de forma segura para a empresa prosperar. Hoje em dia é difícil sobreviver ao sistema. Mas se você estiver convicto de que seus conhecimentos são plenos e que tem condições para administrar, desejo boa sorte!"

"Já tentei uma vez, futuramente, quem sabe tentarei novamente."

"Não em Novo Hamburgo."

"Já fiz e não recomendo."

Fonte: Elaborado pelos autores

Evidenciam-se, na sequência, as considerações finais deste estudo.

\section{CONSIDERAÇÕES FINAIS}

O presente trabalho objetivou dar continuidade a um estudo iniciado em maio de 2014 que, em um primeiro momento, contemplou dados demográficos e ambientais dos trabalhadores da área criativa de Novo Hamburgo/RS que, entre outros pontos, demonstrou que grande parte dos trabalhadores criativos da cidade é oriunda das Instituições de Ensino Superior da região. A continuação deste estudo, apresentada anteriormente, visou demonstrar o perfil do profissional hamburguense enquanto criativo, abordando aspectos referentes aos $3 \mathrm{Ts}$ descritos por Florida (2014). A fim de facilitar a compreensão dos resultados da pesquisa, o quadro a seguir estabelece uma síntese dos principais itens ressaltados pelos entrevistados, abordando, sobretudo, as respostas mais sinalizadas pelos respondentes. 
Quadro 4 - Quadro-síntese com as respostas mais sinalizadas na pesquisa

\begin{tabular}{|c|c|c|}
\hline Questão & Resposta & $\begin{array}{c}\text { Respondentes } \\
\text { (em \%) }\end{array}$ \\
\hline $\begin{array}{l}\text { Satisfação com } \\
\text { cursos superiores } \\
\text { em Novo } \\
\text { Hamburgo }\end{array}$ & $\begin{array}{l}\text { Grau de } \\
\text { importância } \\
\text { mais } \\
\text { assinalado: } \\
\text { "4" }\end{array}$ & 32 \\
\hline $\begin{array}{l}\text { Satisfação com } \\
\text { cursos livres em } \\
\text { Novo Hamburgo }\end{array}$ & $\begin{array}{l}\text { Grau de } \\
\text { importância } \\
\text { mais } \\
\text { assinalado: } \\
\text { "3" }\end{array}$ & 36 \\
\hline $\begin{array}{l}\text { Satisfação com } \\
\text { eventos } \\
\text { (congressos, } \\
\text { seminários, } \\
\text { workshops etc) } \\
\text { em Novo } \\
\text { Hamburgo }\end{array}$ & $\begin{array}{l}\text { Grau de } \\
\text { importância } \\
\text { mais } \\
\text { assinalado: } \\
\text { "2" }\end{array}$ & 37 \\
\hline $\begin{array}{l}\text { Satisfação com } \\
\text { cinema em Novo } \\
\text { Hamburgo }\end{array}$ & $\begin{array}{l}\text { Grau de } \\
\text { importância } \\
\text { mais } \\
\text { assinalado: } \\
\text { "2" }\end{array}$ & 34 \\
\hline $\begin{array}{l}\text { Satisfação com } \\
\text { teatro em Novo } \\
\text { Hamburgo }\end{array}$ & $\begin{array}{l}\text { Grau de } \\
\text { importância } \\
\text { mais } \\
\text { assinalado: } \\
\text { "2" }\end{array}$ & 30 \\
\hline $\begin{array}{l}\text { Satisfação com } \\
\text { showsmusicais } \\
\text { em Novo } \\
\text { Hamburgo }\end{array}$ & $\begin{array}{l}\text { Grau de } \\
\text { importância } \\
\text { mais } \\
\text { assinalado: } \\
\text { "3" }\end{array}$ & 27 \\
\hline $\begin{array}{l}\text { Satisfação com } \\
\text { internet banda } \\
\text { larga em Novo } \\
\text { Hamburgo }\end{array}$ & $\begin{array}{l}\text { Grau de } \\
\text { importância } \\
\text { mais } \\
\text { assinalado: } \\
\text { "3" }\end{array}$ & 31 \\
\hline $\begin{array}{l}\text { Qual elemento } \\
\text { você considera } \\
\text { essencial para o } \\
\text { desenvolvimento } \\
\text { de um diferencial } \\
\text { criativo? }\end{array}$ & $\begin{array}{l}\text { Trocar } \\
\text { experiência } \\
\text { com } \\
\text { profissionais } \\
\text { do ramo. }\end{array}$ & 55 \\
\hline
\end{tabular}

\begin{tabular}{|c|c|c|}
\hline Questão & Resposta & $\begin{array}{c}\text { Respondentes } \\
\text { (em \%) }\end{array}$ \\
\hline $\begin{array}{l}\text { Perante um } \\
\text { problema que } \\
\text { envolva uma } \\
\text { solução criativa, } \\
\text { você ouve } \\
\text { opiniões de } \\
\text { pessoas } \\
\text { desvinculadas à } \\
\text { área da } \\
\text { criatividade? }\end{array}$ & $\begin{array}{l}\text { Sim! } \\
\text { Qualquer } \\
\text { contribuição, } \\
\text { independente } \\
\text { da área, é } \\
\text { sempre bem- } \\
\text { vinda. }\end{array}$ & 93 \\
\hline $\begin{array}{l}\text { Você se } \\
\text { considera } \\
\text { tolerante às } \\
\text { diversidades } \\
\text { culturais em seu } \\
\text { convívio } \\
\text { profissional e } \\
\text { pessoal? }\end{array}$ & $\begin{array}{l}\text { Sim! Sou bem } \\
\text { aberto às } \\
\text { diversidades } \\
\text { culturais. }\end{array}$ & 80 \\
\hline $\begin{array}{l}\text { Os aparatos } \\
\text { tecnológicos } \\
\text { existentes } \\
\text { contribuem para } \\
\text { seu } \\
\text { desenvolvimento } \\
\text { criativo? }\end{array}$ & $\begin{array}{l}\text { Sim! A } \\
\text { tecnologia me } \\
\text { ajuda a pensar } \\
\text { "fora da } \\
\text { caixa". }\end{array}$ & 92 \\
\hline $\begin{array}{l}\text { Você considera } \\
\text { Novo Hamburgo } \\
\text { uma cidade } \\
\text { tecnológica? }\end{array}$ & $\begin{array}{l}\text { Em parte! } \\
\text { Temos uma } \\
\text { boa estrutura } \\
\text { tecnológica, } \\
\text { contudo, é } \\
\text { preciso } \\
\text { melhorar } \\
\text { bastante. }\end{array}$ & 59 \\
\hline $\begin{array}{l}\text { Você trocaria de } \\
\text { emprego, } \\
\text { ganhando menos } \\
\text { como funcionário } \\
\text { em uma startup, } \\
\text { apenas pela } \\
\text { oportunidade de } \\
\text { exercitar os seus } \\
\text { talentos? }\end{array}$ & $\begin{array}{l}\text { Sim! O que } \\
\text { vale é a } \\
\text { realização } \\
\text { pessoal! }\end{array}$ & 49 \\
\hline $\begin{array}{l}\text { Você deixaria um } \\
\text { emprego estável e } \\
\text { com bom salário } \\
\text { para abrir uma } \\
\text { empresa própria, } \\
\text { onde pudesse } \\
\text { colocar em } \\
\text { prática as suas } \\
\text { ideias criativas? }\end{array}$ & $\begin{array}{l}\text { Sim! Tenho } \\
\text { "peito" para } \\
\text { isso! }\end{array}$ & 63 \\
\hline
\end{tabular}

Fonte: Elaborado pelos autores

Uma das contribuições que perpassam as 
ambiental e análise baseada nos 3Ts - é a relação dos criativos de Novo Hamburgo com a Universidade. $\mathrm{Na}$ análise dos dados, é factível que a classe criativa da cidade é potencializada e fomentada pela existência de uma Instituição de Ensino Superior de grande porte, tanto na localidade, quanto nas cidades próximas. Percebe-se que a Universidade se destaca enquanto território criativo que desenvolve profissionais com potencial para consolidar uma tendência econômica atrelada a novos campos, produtos e serviços, bem como colaborar com setores tradicionais da economia (Potts\& Cunningham, 2010).

Ao fim do estudo, constata-se que o mesmo atingiu seus objetivos, contribuindo para uma maior compreensão do panorama criativo na cidade de Novo Hamburgo/RS. Destaca-se o fato de o mesmo ter ultrapassado a meta estabelecida para o número de respondentes da pesquisa que, inicialmente, previa 323 e, ao fim da coleta, atingiu a meta de 339 entrevistados, o que, de forma lídima, contribuiu, ainda mais, para a validação dos resultados.

\section{REFERÊNCIAS}

ASHEIM, Bjørn; HANSEN, HøgniKals $\varnothing$. (2009).Knowledge Bases, Talents, and Contexts: On the Usefulness of the Creative Class Approach in Sweden.

EconomicGeography, n. 85, v. 4, p. 425-442.

BENDASSOLLI, Pedro F. (2009). Indústrias criativas:definição, limites e possibilidades. RAE, São Paulo, v. 49, n.1, jan./mar.
DEHEINZELIN, Lala. (2011). Economia Criativa e métodos para dar uma mão ao futuro. Redige, v. 2, n. 02, ago.

FELÍCIO, Alexandre. (2014). Pessoas criativas são mais felizes e ganham mais. São Paulo: Audiolivro.

\section{FIRJAN. (2014). Mapeamento da Industria}

Criativa no Brasil. Disponível em:

$<$ http://www.firjan.org.br/economiacriativa/pag es/default.aspx>. Acessoem: 01 mai. 2014.

FLORIDA, Richard. (2014). Rise of the Creative Class - Revisited. EUA: Basic Books.

HOWKINS, John. (2002). The Creativy Economy: How People make Money from Ideas. EUA: Penguin Books.

JUNCO, Reynol. (2013).Inequalities in Facebook use. Computers in Human Behavior, v. 29(6), p.2328-2336.

NICOLACI-DA-COSTA, Ana Maria. (2011). O talento jovem, a internet e o mercado de trabalho da "economia criativa".

Psicologia\&Sociedade, v. 23 (3), p. 554-563.

POTTS, J.; CUNNINGHAM, S. (2010). Four models of the creative industries. Revue d'Economie Politique, volume 120, issue 1, january, p. 163-180.

PRODANOV, Cleber Cristiano; FREITAS, Ernani Cesar de. (2013). Metodologia do trabalho científico:métodos e técnicas da pesquisa e do trabalho acadêmico. 2. ed. Novo Hamburgo, RS: Feevale.

REIS, Ana Carla Fonseca. (2012). Cidades Criativas - da Teoria À Prática. São Paulo: Sesi.

RYAN, Tracii; XENOS, Sophia. (2011).Who uses Facebook? An investigation into the relationship between the Big Five, shyness, narcissism, loneliness, and Facebook usage. Computers in HumanBehavior, v. 27(5), p.1658-1664. 
SCHEMES, Claudia; PRODANOV, Cleber Cristiano; THÖN, Ida Helena; MARTINS, Rodrigo Perla. (2005). Memória do setor coureiro-calçadista: pioneiros e empreendedores do Vale do Rio dos Sinos. NovoHamburgo, RS: Feevale.

SIMONTON, Dean Keith. (2000).Creativity:

Cognitive, Personal, Developmental and Social Aspects. American Psychologist, v. 55, n. 1, p. 151-158. 